\title{
Augmentation of keratinized tissue at tooth and implant sites by using autogenous grafts and collagen-based soft-tissue substitutes
}

Thoma, Daniel S ; Lim, Hyun-Chang ; Paeng, Kyeong-Won ; Kim, Myong Ji ; Jung, Ronald E ; Hämmerle, Christoph H F ; Jung, Ui-Won

Abstract: AIM To investigate the effect of three treatment modalities on the gain of keratinized tissue (KT) at tooth and implant sites in dogs. MATERIALS AND METHODS In five dogs, the distal roots of the mandibular second, third and fourth premolars were extracted, while the mesial roots were maintained. After 2 months of healing, implants were placed with KT excision. After another 2 months of healing, free gingival grafts, collagen-based matrices and apically positioned flap only were applied. The height of KT was measured during implant placement, immediately before soft-tissue grafting and after 10, 30 and 60 days. RESULTS Two months after KT excision, spontaneous KT regrowth was greater at tooth sites than at implant sites (median, $2.0 \mathrm{~mm}$ vs. $1.1 \mathrm{~mm}$ ). The outcomes of soft-tissue grafting at implant sites favoured the free gingival graft treatment, with a greater final median height (5.0-5.5 mm) and increase in KT (4.0-4.2 mm). Locations of the recipient sites significantly influenced KT regeneration at both tooth and implant sites. CONCLUSIONS At implant sites, the free gingival graft treatment led to higher KT regeneration. At tooth sites, however, the differences between the three treatment modalities seemed clinically irrelevant.

DOI: https://doi.org/10.1111/jcpe.13194

Posted at the Zurich Open Repository and Archive, University of Zurich

ZORA URL: https://doi.org/10.5167/uzh-176993

Journal Article

Accepted Version

Originally published at:

Thoma, Daniel S; Lim, Hyun-Chang; Paeng, Kyeong-Won; Kim, Myong Ji; Jung, Ronald E; Hämmerle, Christoph H F; Jung, Ui-Won (2020). Augmentation of keratinized tissue at tooth and implant sites by using autogenous grafts and collagen-based soft-tissue substitutes. Journal of Clinical Periodontology, 47(1):64-71.

DOI: https://doi.org/10.1111/jcpe.13194 
DR. DANIEL STEFAN THOMA (Orcid ID : 0000-0002-1764-7447)

DR. HYUN-CHANG LIM (Orcid ID : 0000-0001-7695-1708)

PROF. UI-WON JUNG (Orcid ID : 0000-0001-6371-4172)

Article type : Original Article Pre-Clinical Sciences

Augmentation of keratinized tissue at tooth and implant sites by using autogenous grafts and collagen-based soft-tissue substitutes

Running title: Keratinized tissue augmentation

Daniel S. Thoma ${ }^{1 *}$, Hyun-Chang Lim ${ }^{1,2 *}$, Kyeong-Won Paeng ${ }^{3}$, Myong Ji Kim ${ }^{3}$, Ronald E. Jung $^{1}$, Christoph HF. Hämmerle ${ }^{1}$,Ui-Won Jung ${ }^{3}$

This article has been accepted for publication and undergone full peer review but has not been through the copyediting, typesetting, pagination and proofreading process, which may lead to differences between this version and the Version of Record. Please cite this article as doi: $\underline{10.1111 / \text { jepe. } 13194}$

This article is protected by copyright. All rights reserved 


\section{Authors' affiliations:}

${ }^{1}$ Clinic of Fixed and Removable Prosthodontics and Dental Material Science, University of Zurich, Zurich, Switzerland

${ }^{2}$ Department of Periodontology, Periodontal-Implant Clinical Research Institute, School of Dentistry, Kyung Hee University, Seoul, Republic of Korea

${ }^{3}$ Department of Periodontology, Research Institute for Periodontal Regeneration, Yonsei University College of Dentistry, Seoul, Republic of Korea

${ }^{*}$ These authors contributed equally to this study.

\section{Corresponding author:}

Prof. Ui-Won Jung

Department of Periodontology, Research Institute for Periodontal Regeneration, Yonsei University College of Dentistry, 50-1 Yonsei-ro, Seodaemun-gu, Seoul 03722, Korea

E-mail:drjew@yuhs.ac,Tel: +82-2-2228-3185,Fax:+82-2-392-0398

\section{Acknowledgments:}

The authors express their thanks to the researchers at the Department of Periodontology, Research Institute of Periodontal Regeneration, Yonsei University, College of Dentistry, Seoul, Korea, for their support during the animal experiments. The extensive statistical advice provided by Prof. Dr. Jürg Hüsler (Clinic of Fixed and Removable Prosthodontics and Dental Material Science, University of Zurich) is also highly appreciated. The experimental materials were kindly supplied by Geistlich Pharma.

\section{Source of funding:}

This work was supported by the National Research Foundation of Korea (NRF) grant funded by the Korean government (Ministry of Science, ICT \& Future Planning) (No. NRF2017R1A2B2002537).

This article is protected by copyright. All rights reserved 


\section{Conflicts of interest}

The authors have stated explicitly that there are no conflicts of interest in connection with this article.

This article is protected by copyright. All rights reserved 


\section{Abstract}

Aim: To investigate the effect of three treatment modalities on the gain of keratinized tissue (KT) at tooth and implant sites in dogs.

Materials and methods: In five dogs, the distal roots of the mandibular second, third, and fourth premolars were extracted, while the mesial roots were maintained. After 2 months of healing, implants were placed with KT excision. After another 2 months of healing, free gingival grafts, collagen-based matrices, and apically positioned flap only were applied. The height of KT was measured during implant placement, immediately before soft-tissue grafting, and after 10, 30, and 60 days.

Results: Two months after KT excision, spontaneous KT regrowth was greater at tooth sites than at implant sites (median, $2.0 \mathrm{~mm}$ vs. $1.1 \mathrm{~mm}$ ). The outcomes of soft-tissue grafting at implant sites favored the free gingival graft treatment, with a greater final median height $(5.0-5.5 \mathrm{~mm})$ and increase in $\mathrm{KT}(4.0-4.2 \mathrm{~mm})$. Locations of the recipient sites significantly influenced KT regeneration at both tooth and implant sites.

Conclusions: At implant sites, the free gingival graft treatment led to higher KT regeneration. At tooth sites, however, the differences between the three treatment modalities seemed clinically irrelevant.

Keywords: Dental implant, Tooth, Autografts, Tissue scaffolds, Keratinized tissue

This article is protected by copyright. All rights reserved 


\section{Clinical relevance}

\section{Scientific rationale for study}

There is a dearth of studies comparing treatment modalities, such as apically positioned flap (APF) only, free gingival graft (FGG), or a xenogenic collagen matrix (XCM), for keratinized tissue $(\mathrm{KT})$ regeneration around tooth and implant sites in the same experimental model.

\section{Principal findings}

Implant sites favored the FGG treatment without a statistically significant difference, but tooth sites demonstrated similar KT regeneration, irrespective of the treatment modalities. The location of the recipient site had a significant impact on KT regeneration.

\section{Practical implications}

Different healing potentials for KT regeneration between tooth and implant sites should be considered. 


\section{Introduction}

The importance of keratinized tissue (KT) around natural teeth had been controversial (Mehta, P. and Lim, L. P., 2010), but extensive research demonstrated that the absence of KT does not deteriorate periodontal health (Dorfman, H. S. et al., 1982, Wennstrom, J. and Lindhe, J., 1983b, a). Nevertheless, KT might be necessary in some clinical situations, such as prosthetic reconstructions with subgingival margins, a high frenulum, and pre-orthodontic therapy (Ericsson, I. and Lindhe, J., 1984, Hangorsky, U. and Bissada, N. F., 1980).

A similar controversy surrounds dental implants. The absence of KT was not associated with the quality of plaque control, peri-implant health, and marginal bone loss (Lim, H. C. et al., 2019, Wennstrom, J. L. et al., 1994). However, others demonstrated increased plaque accumulation, a higher gingival index, increased probing depth, increased bleeding on probing, more recession, and even marginal bone loss (Bouri, A., Jr. et al., 2008, Boynuegri, D. et al., 2013, Schrott, A. R. et al., 2009). The proceedings of the world workshop in 2017 stated that the minimum dimension of KT for maintaining peri-implant health and preventing peri-implant diseases was still controversial (Berglundh, T. et al., 2018)

Recently, the importance of KT around dental implants has been emphasized. In a 10-year prospective study, a lack of KT in the posterior mandible increased the soreness during oral hygiene practice, as well as the number of events requiring antibiotic and surgical therapy to manage biological complications (Roccuzzo, M. et al., 2016). This finding, similar to that observed at tooth sites, indicated that the presence of KT might be necessary in specific clinical situations.

Methods for increasing KT include an apically positioned flap (APF), as well as APF with an autogenous graft or a xenogenic collagen matrix (XCM) (Lim, H. C. et al., 2018, Thoma, D. S. et al., 2018, Thoma, D. S. et al., 2009). Autogenous tissue (either a free gingival graft or subepithelial connective tissue graft) is considered a standard of care, but there has been effort to replace autogenous tissue with alternative materials for reducing patient morbidity (Sanz, M. et al., 2009, Schmitt, C. M. et al., 2016). However, little information is available in terms of comparative studies among the above treatment modalities around tooth and implant sites in the same experimental model.

Interestingly, previous studies have not considered the role of the KT band as a part of the This article is protected by copyright. All rights reserved 
flap. The KT band could contribute to wound stabilization and assist KT regeneration when the flap with the KT band is fixed apically.

Therefore, the present study aimed to (i) comparatively evaluate three treatment modalities for KT regeneration, i.e., autogenous tissue (FGG), collagen-based matrices (XCM), or spontaneous healing (APF) at tooth and implant sites in a preclinical experimental model, and (ii) investigate the role of the KT band as part of the flap in treatment outcomes.

\section{Materials and methods}

\section{Animals}

This randomized controlled preclinical study included five Mongrel dogs ( $>2$ years old) weighing $12-17 \mathrm{~kg}$. All dogs were kept in a purpose-designed room for experimental animals, and provided access to water ad libitum and soft diet during the study period. The study protocol was approved by the Institutional Animal Care and Use Committee, Yonsei Medical Research Center, Seoul, South Korea (Approval no. 2016-0293). This article was written in accordance with the ARRIVE guidelines (Kilkenny, C. et al., 2010).

\section{Surgical procedures}

Surgical setting and post-surgical care are included in Appendix 1.

The surgical protocols were as follows (Fig. 1).

Tooth extraction

The distal roots of the mandibular second, third, and fourth premolars (P2, P3, and P4, respectively) were extracted by hemi-section on both sides. The pulp tissues of the mesial roots were extirpated, and the root canals were filled with mineral trioxide aggregate (ProRoot ${ }^{\circledR}$ MTA, Dentsply Sirona Korea, Seoul, Korea). The access hole was closed with resin cement.

\section{Implant placement and KT excision}

After 2 months, implant placement and KT excision were performed. Following sulcular incisions around the teeth (the mesial roots of $\mathrm{P} 2 / \mathrm{P} 3 / \mathrm{P} 4$ ) and crestal incisions on the edentulous area (the area of the distal roots of P2/P3/P4), two vertical incisions were made at This article is protected by copyright. All rights reserved 
the mid-buccal area of the mandibular first molar (M1) and P1. Thereafter, total excision of the KT band was performed on one side of the mandible. On the other side, $1 \mathrm{~mm}$ of the KT band above the mucogingival junction (MGJ) was retained after excision. Subsequently, twopiece dental implants (Neo CMI IS-II $\varnothing 4.0 \times 8.5 \mathrm{~mm}$, NeoBiotech, Seoul, Korea) were placed. The final level of the implant shoulder was at the buccal bone crest level. Healing abutments $(\varnothing 4.8 \times 5 \mathrm{~mm})$ were connected to the implants for transmucosal healing. The flaps were sutured around the healing abutment and teeth. Therefore, no KT band was present on the buccal side around the teeth and abutments on one side of the mandible (no-KT side), whereas $1 \mathrm{~mm}$ of the KT band was present on the other side of the mandible (1 mm of KT side).

\section{Soft-tissue augmentation}

Two months later, soft-tissue augmentation surgeries were performed. On the no-KT side of the mandible, a horizontal incision was made at the level of the MGJ, extending from the mid-buccal surface of the mandibular first premolar (P1) to the mid-buccal surface of the M1; moreover, two vertical incisions were made, and a partial-thickness alveolar mucosal flap, leaving the periosteum on the bone surface, was raised without including KT. On the contralaterial side ( $1 \mathrm{~mm}$ of $\mathrm{KT}$ left), two vertical incisions as well as sulcular incisions were made around the mesial roots of $\mathrm{P} 2 / \mathrm{P} 3 / \mathrm{P} 4$ and the implants (distal roots of $\mathrm{P} 2 / \mathrm{P} 3 / \mathrm{P} 4$ ). Subsequently, a partial-thickness flap with the KT band was raised. The flap was then sutured using horizontal mattress sutures at the apical area of the periosteum bed.

Three treatment modalities were then randomly assigned to the tooth and implant sites: group XCM (Mucograft, Geistlich Pharma, Wolhusen, Switzerland); group FGG: an autogenous FGG harvested from the buccal side of M1/M2; and group APF: no further augmentation on the exposed periosteum.

The graft materials (FGG and XCM) were trimmed to ensure sufficient length to cover the recipient site (approximately $15 \mathrm{~mm}$ in width and $5 \mathrm{~mm}$ in height). The graft materials were then sutured to the exposed periosteum by using single interrupted sutures and cross mattress sutures. After suturing the FGG and XCM, approximately $5 \mathrm{~mm}$ of the periosteum was left exposed apically to prevent mobilization of the augmented sites (Fig. 2).

This resulted in the following six treatment modalities at the tooth and implant sites:

This article is protected by copyright. All rights reserved 
i) FGG with/without the KT band on the APF: FGG_KT/FGG_NKT,

ii) XCM with/without the KT band on the APF: XCM_KT/XCM_NKT, and

iii) APF with/without the KT band on the APF: APF_KT/APF_NKT.

The sutures were removed 10 days later.

\section{Follow-up examinations}

At implant placement, immediately before soft-tissue graft surgery, and at 10 days (suture removal), 30 days, and 60 days (sacrifice), the height of KT (from the gingival/mucosal margin to the MGJ) was measured at the midbuccal area of the tooth/implant by using a caliper to the nearest $0.1 \mathrm{~mm}$.

In order to minimize measurement error, two researchers (K-W. P and M.J.K) jointly conducted clinical measurement under same setting. Prior to starting measurement, a senior researcher (U-W. J) guided how to determine MGJ. Then, one researcher (M.J.K) firstly detected MGJ and the other (K-W. P) confirmed it.

\section{Sacrifice}

At 60 days after soft-tissue augmentation (Fig. 2), the dogs were sacrificed.

\section{Statistical analysis}

The metric variables are described as means and standard deviations, as well as medians and quartiles. To analyze the impact of the recipient (tooth or implant), KT band as part of the flap, treatment modality (FGG, XCM, or APF), and site (P2, P3, or P4), we applied mixed models because of the dependence of the data within a dog. A model was selected via backward selection of significant factors, and validation of the model assumptions. If a significant factor was observed, pairwise comparisons of the subgroups were performed by applying the Bonferroni correction for multiple subgroup testing. A $p<0.05$ was considered significant (SAS 9.4; SAS Cary N.C. USA).

\section{Results}

None of dogs developed local infections during the study period.

This article is protected by copyright. All rights reserved 


\section{Clinical healing}

Immediately before soft-tissue graft surgery

At 2 months after KT excision, varying degrees of KT regrowth were observed with a welldiscernible MGJ. In general, tooth sites demonstrated greater amount of KT formation compared to implant sites.

At 10 days after soft-tissue graft surgery

Newly regenerated, reddish tissues were observed at the recipient sites. Most of the sites grafted with FGGs were light reddish, with a slightly pronounced contour. Small remnants of $\mathrm{XCM}$ were observed at sites grafted with XCM. The color of the APF sites was more reddish than at the other sites. No apparent differences were noted between tooth and implant sites.

At 30 days after soft-tissue graft surgery

Varying degrees of tissue maturation were observed. Some sites demonstrated complete keratinization with a distinct transition to the non-keratinized mucosa. Other sites demonstrated a combination of immature and mature KT. The recipient beds demonstrated some shrinkage and scar-like linear tissue formation apically. Group FGG could be clearly distinguished from the other treatment groups. The appearances of groups XCM and APF were similar.

At 60 days after soft-tissue graft surgery

Tissue maturation and keratinization seemed almost complete. The shrinkage of the recipient bed was more pronounced at P2, irrespective of the treatment modality. A scar-like tissue band was still discernible apically. The texture of the FGG sites showed less blending with the adjacent tissues compared to XCM and APF only sites.

\section{Measurements}

All clinical measurements are presented in Tables 1 and 2, and Figures 3 and 4.

\section{Rebound effect following KT excision at tooth and implant sites}

In the groups wherein KT had been completely resected, the median (Q1, Q3) KT height was $1.8 \mathrm{~mm}(1.7,2.4)$ at tooth sites and $0.6 \mathrm{~mm}(0,1.0)$ at implant sites prior to soft-tissue This article is protected by copyright. All rights reserved 
grafting. In groups wherein $1 \mathrm{~mm}$ of KT was left, the median height was $2.2 \mathrm{~mm}(1.9,2.8)$ at tooth sites and $1.5 \mathrm{~mm}(1.2,2.0)$ at implant sites. All tooth sites showed the KT band, but six implant sites presented no KT in case of complete KT resection.

KT regrowth was significantly greater at tooth sites than at implant sites in groups when KT was completely resected ( $p=0.0145$ with Bonferroni correction). Moreover, KT regrowth was significantly greater at tooth sites where $1 \mathrm{~mm}$ of KT was left than at implant sites with KT completely resected ( $p=0.0063$ with Bonferroni correction).

\section{Effect of soft-tissue augmentation using FGG, XCM, and APF only at 10 days}

At tooth sites, a greater median KT height was observed in groups FGG (FGG_NKT: 13.9 mm [13.0, 16.9]; FGG_KT: $12.3 \mathrm{~mm}[10.1,12.5])$ and groups XCM (XCM_NKT: $13.9 \mathrm{~mm}$ $[12.0,15.1]$; XCM_KT: $13.0 \mathrm{~mm}[10.6,14.1])$ than in groups APF (APF_NKT: $12.0 \mathrm{~mm}$ $[10.4,12.7]$; APF_KT: $11.4 \mathrm{~mm}[9.9,14.7])$.

At implant sites in groups NKT, the median KT height ranged between $11.9 \mathrm{~mm}(10.7,14.7)$ for group XCM and $13.8 \mathrm{~mm}(11.6,14.0)$ for group FGG. In groups KT, the median KT height ranged between $10.8 \mathrm{~mm}(10.3,11.4)$ for group FGG and $11.9 \mathrm{~mm}(10.1,12.2)$ for group APF.

KT height was significantly associated with the presence of the KT band in the apically secured flap ( $p=0.0083$ ). The location also demonstrated a statistically significant impact on KT height ( $p=0.009$ ), but pairwise comparisons revealed no statistically significant difference with Bonferroni correction between groups ( $p=0.020$ for $\mathrm{P} 2$ vs. $\mathrm{P} 3, p=0.0065$ for $\mathrm{P} 2$ vs. $\mathrm{P} 4$ at tooth sites, without Bonferroni correction). The interaction between recipient site (tooth or implant) and location was significant $(p=0.0296)$.

\section{KT height at sacrifice (60 days)}

At tooth sites, the median KT height in groups NKT was the greatest in group XCM_NKT $(5.2 \mathrm{~mm}[4.7,5.6])$, followed by group APF_NKT $(4.7 \mathrm{~mm}[3.4,7.2])$ and group FGG_NKT (4.1 mm [4.0, 6.3]). The median KT height in groups KT ranged between $5.2 \mathrm{~mm}(3.7,5.3)$ in group FGG_KT and 5.9 mm $(2.3,7.3)$ in group APF_KT.

At implant sites in groups NKT, the greatest median KT height was observed in group FGG_NKT $(5.0 \mathrm{~mm}[4.3,5.5])$, followed by group XCM_NKT $(4.4 \mathrm{~mm}[3.3,4.5])$ and group This article is protected by copyright. All rights reserved 
APF_NKT $(4.2 \mathrm{~mm}[3.5,5.4])$. In groups KT, the height was similar among the groups, ranging between $5.1 \mathrm{~mm}(4.2,6.1)$ in group APF_KT and $5.5 \mathrm{~mm}(3.9,7.0)$ in group FGG_KT.

Among the factors, only location demonstrated a significant influence on KT height ( $p=0.0092$ for $\mathrm{P} 2$ vs. $\mathrm{P} 3, p=0.0036$ for $\mathrm{P} 2$ vs. $\mathrm{P} 4$, with Bonferroni correction).

Changes in KT after soft-tissue augmentation and at sacrifice (60 days)

The median increase in KT at tooth sites showed minor differences between groups NKT (range: $3.2 \mathrm{~mm}[2.9,3.5]$ for group XCM_NKT - $2.7 \mathrm{~mm}[2.0,4.6]$ for group APF_NKT). Among groups KT, group XCM_KT showed the greatest KT regeneration $(4.1 \mathrm{~mm}$ [2.3, 4.2]), followed by group APF_KT $(2.9 \mathrm{~mm}[0.9,4.5])$ and group FGG_KT (2.5 mm [1.9, 2.6]).

The median KT increase at implant sites was greater in groups FGG than in the other groups, regardless of whether the KT band was included in the flap: increase in KT of $4.2 \mathrm{~mm}$ (3.7, $5.5)$ in group FGG_NKT and of $4.0 \mathrm{~mm}(1.9,5.0)$ in group FGG_KT. In the other two groups, the increase ranged between $3.2 \mathrm{~mm}(2.8,4.7)$ for group APF_KT and $3.7 \mathrm{~mm}(2.3$, 4.2) for group APF_NKT.

The increase in KT was significantly influenced only by the location ( $p=0.0444$ for P2 vs. P3, $p=0.0087$ for $\mathrm{P} 2$ vs. P4, with Bonferroni correction). Further pairwise intergroup comparisons revealed a significant difference between $\mathrm{P} 2$ and $\mathrm{P} 3$ at tooth sites ( $p=0.0332$ with Bonferroni correction), between $\mathrm{P} 4$ at implant sites and $\mathrm{P} 2$ at tooth sites $(p=0.0177$ with Bonferroni correction), and between P2 at tooth sites and P3 at implant sites ( $p=0.0359$ with Bonferroni correction).

\section{Discussion}

The present study revealed the effect of KT excision and soft-tissue grafting at tooth and implant sites. After KT excision, a spontaneous rebound effect resulted in greater KT regeneration at tooth sites than at implant sites. The outcomes of soft-tissue grafting (i) favored the FGG treatment at implant sites in terms of the final median height and the increase in KT; (ii) at tooth sites, exhibited minimal differences in KT regeneration between This article is protected by copyright. All rights reserved 
the three treatment modalities and between sites with and without the KT band as part of the flap; (iii) were influenced by location; and (iv) favored the XCM and APF treatments over the FGG treatment in terms of esthetic appearance.

Healing after gingival excision around natural teeth was previously evaluated (Wennstrom, J., 1983, Wennstrom, J. and Lindhe, J., 1983b). In those studies, buccal KT was removed up to 1 $\mathrm{mm}$ below the MGJ and the underlying periosteum was left in situ. Over time, KT regrowth was observed: $2.05 \mathrm{~mm}$ in a clinical study and $1.5 \mathrm{~mm}$ in a preclinical study (Wennstrom, J., 1983, Wennstrom, J. and Lindhe, J., 1983b). At tooth sites in the present study, the median KT regrowth was $1.84 \mathrm{~mm}$ in total $\mathrm{KT}$ excision and $2.17 \mathrm{~mm}$ in case of $1 \mathrm{~mm}$ of the KT band left at 2 months after excision (pooled median value: $2.0 \mathrm{~mm}$ ), thus demonstrating little influence of the remaining KT band. However, implant sites showed significantly less KT regrowth (pooled median value: $1.1 \mathrm{~mm}$ ) than did tooth sites. KT regrowth was lesser in implants without KT bands than in implants having presurgical KT bands (0.6 vs. $1.5 \mathrm{~mm}$ ). Our results indicate that the connective tissue below the keratinized epithelium or the periodontal ligament has the potential to induce keratinization (Karring, T. et al., 1975, Sculean, A. et al., 2014).

The healing after soft-tissue grafting at implant sites tended to favor the FGG treatment. At implant sites, FGG led to greater KT formation in terms of the final height and increase compared to the other treatments. This might be due to a small connective tissue layer included in the FGG. Evidence suggested that the connective tissue has the genetic information to determine epithelial differentiation (Karring, T. et al., 1975).

Previous studies compared FGG to $\mathrm{XCM}$ in various situations to evaluate the potential replacement of FGG with XCM (Lim, H. C. et al., 2018, Lorenzo, R. et al., 2012, Sanz, M. et al., 2009, Schmitt, C. M. et al., 2016, Thoma, D. S. et al., 2018). Despite the predictability of FGG, increased donor-site morbidity and increased discomfort are problematic (Thoma, D. S. et al., 2009). Thus, XCM, which serves as a scaffold for soft-tissue augmentation, was introduced (Lorenzo, R. et al., 2012). The three-dimensional structure of XCM facilitates the ingrowth and repopulation of cellular and vascular components, leading to a transformation into KT (Jung, R. E. et al., 2011, Thoma, D. S. et al., 2012). Previous studies generally demonstrated no significant difference between FGG and XCM in terms of KT regeneration (Lorenzo, R. et al., 2012, Sanz, M. et al., 2009, Schmitt, C. M. et al., 2016, Thoma, D. S. et This article is protected by copyright. All rights reserved 
al., 2018), except for one study (Lim, H. C. et al., 2018). This trend is in line with that seen in the present study. Although the final height and increase of KT favored the FGG treatment at implant sites, the intergroup differences did not reach statistical significance.

At tooth sites, FGG did not lead to better KT regeneration than did the other treatments. Rather, XCM resulted in a greater final height and increase of KT. Such a difference between tooth and implant sites might be derived from (i) the periodontal ligament at tooth sites and (ii) the different level of the cementoenamel junction of natural teeth and the location of the implant platform with respect to the bone crest.

This study revealed an influence of the location on KT regeneration. The P2 site demonstrated significantly less final height and increase of KT. In the mandible of dogs, a highly pronounced frenular attachment is generally found around the P1 and P2 sites. This attachment is histologically composed of fibrous connective tissue and a few muscle fibers (Gartner, L. P. and Schein, D., 1991). During the healing period in the present study, this attachment demonstrated a tendency to relapse, thereby jeopardizing KT regeneration. Clinically, this anatomic structure around the P2 area can be considered an analogue of muscle pulling. Previously, high muscle attachment was suspected to be a factor resulting in inferior KT regeneration (Sanz, M. et al., 2009). Moreover, in a retrospective study, XCM demonstrated higher shrinkage than did FGG for implants in the posterior mandible (Lim, H. C. et al., 2018).

It had been initially expected that the KT band included in the apically secured flap around tooth and implant sites contributed to the final KT height, because it may assist in firm stabilization of the apically secured flap and induce keratinization. Such a hypothesis was proven wrong at 10 and 60 days. A statistically significant difference produced by the KT band at 10 days (favoring the NKT groups over the KT groups) was possibly due to the presence of KT around teeth/implants, rather than the KT band itself in the apically secured flap. Eventually, within the same treatment, minor differences were observed in the increase in $\mathrm{KT}$ between groups KT and NKT.

The esthetic appearance of the augmented sites in the present study concurs with that reported in previous studies (Lim, H. C. et al., 2018, Lorenzo, R. et al., 2012, Sanz, M. et al., 2009). FGG sites had a disharmonized appearance than did XCM and APF sites. Uneven and scarlike gingival/mucosal tissue in esthetic areas resulting from the FGG treatment could This article is protected by copyright. All rights reserved 
compromise the esthetic outcome and decrease patient satisfaction.

One of the limitations of the present preclinical study was to adjoin the surgical areas for implant and tooth sites. The healing of the implant site might be influenced by the tooth site and vice versa. Second, the rebound of keratinized tissue at implant and tooth sites of groups KT and NKT may be a confounder in interpreting the results of the present study. However, it should be taken into account: i) considering the sulcus depth in dogs (1-3 mm) (Gorrel, C. E. and Hale, F. A., 2012), the amount of KT rebound $(<1 \mathrm{~mm})$ at implant sites in groups NKT mostly belonged to the non-attached mucosa, ii) more than half of the KT rebound appeared to still belong to the free gingiva at tooth sites of the groups NKT, even though the amount of rebound at tooth sites was greater compared to the implant sites and, iii) even if the rebounded KT had been removed, a similar rebound tendency might have been interplayed during the healing phase after the soft tissue augmentation. Third, there was a lack of behavioral control for the experimental animals compared to human patients.

\section{Conclusion}

After KT excision, the spontaneous KT regrowth was greater at tooth sites than at implant sites. The FGG treatment demonstrated a tendency towards higher KT regeneration at implant sites, but without significant differences compared to the other treatments. At tooth sites, the effect of treatment modalities appeared clinically irrelevant, presumably because of the periodontal ligament.

This article is protected by copyright. All rights reserved 


\section{References}

Berglundh, T., Armitage, G., Araujo, M. G., Avila-Ortiz, G., Blanco, J., Camargo, P. M., Chen, S., Cochran, D., Derks, J., Figuero, E., Hammerle, C. H. F., Heitz-Mayfield, L. J. A., Huynh-Ba, G., Iacono, V., Koo, K. T., Lambert, F., McCauley, L., Quirynen, M., Renvert, S., Salvi, G. E., Schwarz, F., Tarnow, D., Tomasi, C., Wang, H. L. \& Zitzmann, N. (2018) Periimplant diseases and conditions: Consensus report of workgroup 4 of the 2017 World Workshop on the Classification of Periodontal and Peri-Implant Diseases and Conditions. $J$ Clin Periodontol 45 Suppl 20, S286-S291. doi:10.1111/jcpe.12957.

Bouri, A., Jr., Bissada, N., Al-Zahrani, M. S., Faddoul, F. \& Nouneh, I. (2008) Width of keratinized gingiva and the health status of the supporting tissues around dental implants. Int J Oral Maxillofac Implants 23, 323-326.

Boynuegri, D., Nemli, S. K. \& Kasko, Y. A. (2013) Significance of keratinized mucosa around dental implants: a prospective comparative study. Clin Oral Implants Res 24, 928933. doi:10.1111/j.1600-0501.2012.02475.x.

Dorfman, H. S., Kennedy, J. E. \& Bird, W. C. (1982) Longitudinal evaluation of free autogenous gingival grafts. A four year report. $J$ Periodontol 53, 349-352. doi:10.1902/jop.1982.53.6.349.

Ericsson, I. \& Lindhe, J. (1984) Recession in sites with inadequate width of the keratinized gingiva. An experimental study in the dog. J Clin Periodontol 11, 95-103.

Gartner, L. P. \& Schein, D. (1991) The superior labial frenum: a histologic observation. Quintessence Int 22, 443-445.

Gorrel, C. E. \& Hale, F. A. (2012) Oral and Maxillofacial Surgery in Dogs and Cats. Elsevier Saunders.

Hangorsky, U. \& Bissada, N. F. (1980) Clinical assessment of free gingival graft effectiveness on the maintenance of periodontal health. $J$ Periodontol 51, 274-278. doi:10.1902/jop.1980.51.5.274.

Jung, R. E., Hurzeler, M. B., Thoma, D. S., Khraisat, A. \& Hammerle, C. H. (2011) Local tolerance and efficiency of two prototype collagen matrices to increase the width of keratinized tissue. J Clin Periodontol 38, 173-179. doi:10.1111/j.1600-051X.2010.01640.x. Karring, T., Lang, N. P. \& Loe, H. (1975) The role of gingival connective tissue in determining epithelial differentiation. $J$ Periodontal Res 10, 1-11.

Kilkenny, C., Browne, W., Cuthill, I. C., Emerson, M., Altman, D. G. \& Group, N. C. R. R. This article is protected by copyright. All rights reserved 
G. W. (2010) Animal research: reporting in vivo experiments: the ARRIVE guidelines. $\mathrm{Br} J$ Pharmacol 160, 1577-1579. doi:10.1111/j.1476-5381.2010.00872.x.

Lim, H. C., An, S. C. \& Lee, D. W. (2018) A retrospective comparison of three modalities for vestibuloplasty in the posterior mandible: apically positioned flap only vs. free gingival graft vs. collagen matrix. Clin Oral Investig 22, 2121-2128. doi:10.1007/s00784-017-2320-y.

Lim, H. C., Wiedemeier, D. B., Hammerle, C. H. F. \& Thoma, D. S. (2019) The amount of keratinized mucosa may not influence peri-implant health in compliant patients: a retrospective 5-year analysis. J Clin Periodontol. doi:10.1111/jcpe.13078.

Lorenzo, R., Garcia, V., Orsini, M., Martin, C. \& Sanz, M. (2012) Clinical efficacy of a xenogeneic collagen matrix in augmenting keratinized mucosa around implants: a randomized controlled prospective clinical trial. Clin Oral Implants Res 23, 316-324. doi:10.1111/j.1600-0501.2011.02260.x.

Mehta, P. \& Lim, L. P. (2010) The width of the attached gingiva--much ado about nothing? $J$ Dent 38, 517-525. doi:10.1016/j.jdent.2010.04.007.

Roccuzzo, M., Grasso, G. \& Dalmasso, P. (2016) Keratinized mucosa around implants in partially edentulous posterior mandible: 10 -year results of a prospective comparative study. Clin Oral Implants Res 27, 491-496. doi:10.1111/clr.12563.

Sanz, M., Lorenzo, R., Aranda, J. J., Martin, C. \& Orsini, M. (2009) Clinical evaluation of a new collagen matrix (Mucograft prototype) to enhance the width of keratinized tissue in patients with fixed prosthetic restorations: a randomized prospective clinical trial. $J$ Clin Periodontol 36, 868-876. doi:10.1111/j.1600-051X.2009.01460.x.

Schmitt, C. M., Moest, T., Lutz, R., Wehrhan, F., Neukam, F. W. \& Schlegel, K. A. (2016) Long-term outcomes after vestibuloplasty with a porcine collagen matrix (Mucograft((R))) versus the free gingival graft: a comparative prospective clinical trial. Clin Oral Implants Res 27, e125-e133. doi:10.1111/clr.12575.

Schrott, A. R., Jimenez, M., Hwang, J. W., Fiorellini, J. \& Weber, H. P. (2009) Five-year evaluation of the influence of keratinized mucosa on peri-implant soft-tissue health and stability around implants supporting full-arch mandibular fixed prostheses. Clin Oral Implants Res 20, 1170-1177. doi:10.1111/j.1600-0501.2009.01795.x.

Sculean, A., Gruber, R. \& Bosshardt, D. D. (2014) Soft tissue wound healing around teeth and dental implants. J Clin Periodontol 41 Suppl 15, S6-22. doi:10.1111/jcpe.12206.

Thoma, D. S., Alshihri, A., Fontolliet, A., Hammerle, C. H. F., Jung, R. E. \& Benic, G. I. (2018) Clinical and histologic evaluation of different approaches to gain keratinized tissue This article is protected by copyright. All rights reserved 
prior to implant placement in fully edentulous patients. Clin Oral Investig 22, 2111-2119. doi:10.1007/s00784-017-2319-4.

Thoma, D. S., Benic, G. I., Zwahlen, M., Hammerle, C. H. \& Jung, R. E. (2009) A systematic review assessing soft tissue augmentation techniques. Clin Oral Implants Res 20 Suppl 4, 146-165. doi:10.1111/j.1600-0501.2009.01784.x.

Thoma, D. S., Sancho-Puchades, M., Ettlin, D. A., Hammerle, C. H. \& Jung, R. E. (2012) Impact of a collagen matrix on early healing, aesthetics and patient morbidity in oral mucosal wounds - a randomized study in humans. $J$ Clin Periodontol 39, 157-165. doi:10.1111/j.1600-051X.2011.01823.x.

Wennstrom, J. (1983) Regeneration of gingiva following surgical excision. A clinical study. $J$ Clin Periodontol 10, 287-297.

Wennstrom, J. \& Lindhe, J. (1983a) Plaque-induced gingival inflammation in the absence of attached gingiva in dogs. $J$ Clin Periodontol 10, 266-276.

Wennstrom, J. \& Lindhe, J. (1983b) Role of attached gingiva for maintenance of periodontal health. Healing following excisional and grafting procedures in dogs. J Clin Periodontol 10, 206-221.

Wennstrom, J. L., Bengazi, F. \& Lekholm, U. (1994) The influence of the masticatory mucosa on the peri-implant soft tissue condition. Clin Oral Implants Res 5, 1-8.

This article is protected by copyright. All rights reserved 


\section{Tables}

Table 1. Height of keratinized tissue measured at each time point (in mm)

\section{Group NKT}

\begin{tabular}{lllllll}
\hline \multicolumn{2}{l}{ Tooth site } & \multicolumn{5}{c}{ Implant site } \\
\hline & FGG & XCM & Control & FGG & XCM & Control \\
\hline Baseline & $1.8(1.7,2.3)$ & $1.8(1.7,1.8)$ & $2.2(2.0,2.6)$ & $0.8(0.6,0.8)$ & $0(0,0.5)$ & $0.7(0,1.2)$ \\
& $1.9 \pm 0.6$ & $1.8 \pm 0.4$ & $2.2 \pm 0.5$ & $0.8 \pm 0.7$ & $0.4 \pm 0.7$ & $0.7 \pm 0.7$ \\
\hline 10 days & $13.9(13.0,16.9)$ & $13.9(12.0,15.1)$ & $12.0(10.4,12.7)$ & $13.8(11.6,14.0)$ & $11.9(10.7,14.7)$ & $12.9(10.9,13.8)$ \\
& $14.4 \pm 3.6$ & $13.3 \pm 2.5$ & $12.1 \pm 4.9$ & $13.3 \pm 2.4$ & $12.5 \pm 2.4$ & $13.3 \pm 3.4$ \\
\hline 30 days & $5.7(4.3,6.0)$ & $5.5(5.3,7.5)$ & $7.5(7.2,12.7)$ & $5.0(4.2,6.6)$ & $4.5(3.5,10.3)$ & $8.9(4.3,9.4)$ \\
& $6.6 \pm 3.5$ & $6.9 \pm 3.2$ & $8.8 \pm 3.9$ & $5.7 \pm 2.0$ & $6.6 \pm 4.2$ & $7.4 \pm 3.5$ \\
\hline 60 days & $4.1(4.0,6.3)$ & $5.2(4.7,5.6)$ & $4.7(3.4,7.2)$ & $5.0(4.3,5.5)$ & $4.4(3.3,4.5)$ & $4.2(3.5,5.4)$ \\
& $5.5 \pm 2.3$ & $5.1 \pm 0.7$ & $5.3 \pm 2.6$ & $5.6 \pm 2.0$ & $4.2 \pm 1.0$ & $4.9 \pm 2.2$ \\
\hline
\end{tabular}

\section{Group KT}

\begin{tabular}{lllllll}
\hline & Tooth site & \multicolumn{5}{l}{ Implant site } \\
\hline & FGG & XCM & Control & FGG & XCM & Control \\
\hline Baseline & $2.2(2.0,2.6)$ & $2.4(1.9,2.6)$ & $2.1(1.9,2.8)$ & $2.0(1.5,2.0)$ & $1.4(1.3,1.9)$ & $1.4(1.0,2.0)$ \\
& $2.3 \pm 0.4$ & $2.3 \pm 0.6$ & $2.2 \pm 0.6$ & $1.8 \pm 0.8$ & $1.7 \pm 0.7$ & $1.6 \pm 0.6$ \\
\hline 10 days & $12.3(10.1,12.5)$ & $13.0(10.6,14.1)$ & $11.4(9.9,14.7)$ & $10.8(10.3,11.4)$ & $11.5(9.8,14.0)$ & $11.9(10.1,12.2)$ \\
& $10.7 \pm 2.9$ & $11.7 \pm 3.7$ & $11.6 \pm 3.3$ & $11.4 \pm 1.7$ & $11.1 \pm 3.6$ & $11.4 \pm 1.3$ \\
\hline 30 days & $6.4(4.3,10.7)$ & $8.0(6.7,8.6)$ & $8.5(7.7,9.8)$ & $7.7(6.1,9.2)$ & $7.9(6.7,8.5)$ & $9.0(8.5,9.1)$ \\
& $7.3 \pm 3.6$ & $7.4 \pm 2.4$ & $7.7 \pm 2.9$ & $7.3 \pm 2.3$ & $7.4 \pm 2.0$ & $8.0 \pm 2.4$ \\
\hline \multirow{2}{*}{60 days } & $5.2(3.7,5.3)$ & $5.6(4.2,6.7)$ & $5.9(2.3,7.3)$ & $5.5(3.9,7.0)$ & $5.4(4.2,5.9)$ & $5.1(4.2,6.1)$ \\
& $5.3 \pm 2.8$ & $5.2 \pm 1.9$ & $5.1 \pm 3.0$ & $5.1 \pm 2.7$ & $5.2 \pm 2.5$ & $5.6 \pm 1.9$ \\
\hline
\end{tabular}

Data are presented as median $(\mathrm{Q} 1, \mathrm{Q} 3)$ and mean \pm standard deviation.

Baseline indicates the time immediately before soft-tissue grafting.

NKT, without the keratinized tissue band on the apically secured flap; FGG, free gingival graft; XCM, xenogenic collagen matrix; KT, with the keratinized tissue band on the apically secured flap

This article is protected by copyright. All rights reserved 
Table 2. Changes in keratinized tissue before soft-tissue grafting and after 60 days (in mm)

\begin{tabular}{lllllll}
\hline \multicolumn{3}{l}{ Tooth site } & \multicolumn{5}{l}{ Implant site } \\
\hline & FGG & XCM & Control & FGG & XCM & Control \\
\hline Group_NKT & $2.9(2.4,3.7)$ & $3.2(2.9,3.5)$ & $2.7(2.0,4.6)$ & $4.2(3.7,5.5)$ & $3.3(3.2,4.0)$ & $3.7(2.3,4.2)$ \\
& $3.6 \pm 1.9$ & $3.3 \pm 0.8$ & $3.1 \pm 2.6$ & $4.8 \pm 1.5$ & $3.8 \pm 1.1$ & $4.2 \pm 2.6$ \\
\hline Group_KT & $2.5(1.9,2.6)$ & $4.1(2.3,4.2)$ & $2.9(0.9,4.5)$ & $4.0(1.9,5.0)$ & $3.5(2.7,4.8)$ & $3.2(2.8,4.7)$ \\
& $3.0 \pm 2.8$ & $2.9 \pm 2.0$ & $2.9 \pm 2.7$ & $3.3 \pm 2.1$ & $3.5 \pm 2.0$ & $4.0 \pm 1.7$
\end{tabular}

Data are presented as median $(\mathrm{Q} 1, \mathrm{Q} 3)$ and mean \pm standard deviation.

FGG, free gingival graft; XCM, xenogenic collagen matrix; NKT, without the keratinized tissue band on the apically secured flap; KT, with the keratinized tissue band on the apically secured flap

This article is protected by copyright. All rights reserved 


\section{Figure legends}

Figure 1. Detailed schedule of the surgical procedures. KT, keratinized tissue.

Figure 2. Representative clinical photographs of the groups with and without the keratinized tissue bands on the apically secured flap (groups KT and NKT, respectively). D10, 10 days after soft-tissue grafting; D30, 30 days after soft-tissue grafting; D60, 60 days after soft-tissue grafting (at sacrifice).

Figure 3. Bar graphs showing the median values of keratinized tissue in the groups with the keratinized tissue bands on the apically secured flap (groups KT) at each time point. FGG, group grafted with a free gingival graft; XCM, group grafted with a xenogenic collagen matrix; APF, group with an apically positioned flap only; D0, at the time of soft-tissue grafting; D10, 10 days after soft-tissue grafting; D30, 30 days after soft-tissue grafting; D60, 60 days after soft-tissue grafting (at sacrifice).

Figure 4. Bar graphs showing the median values of keratinized tissue in the groups without the keratinized tissue bands on the apically secured flap (groups NKT) at each time point. FGG, group grafted with a free gingival graft; XCM, group grafted with a xenogenic collagen matrix; APF, group with an apically positioned flap only; D0, at the time of soft-tissue grafting; D10, 10 days after soft-tissue grafting; D30, 30 days after soft-tissue grafting; D60, 60 days after soft-tissue grafting (at sacrifice).

This article is protected by copyright. All rights reserved 


\begin{tabular}{|c|l|l|}
\hline $\begin{array}{c}\text { Extraction } \\
\text { (P2, months }\end{array}$ & $\begin{array}{l}\text { Implant } \\
\text { placement \& }\end{array}$ \\
KT excision
\end{tabular}

2 months

2 months

Soft tissue augmentation 
Before soft tissue grafting $\quad$ After soft tissue grafting

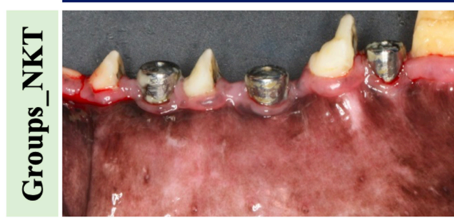

${ }^{\mathrm{P} 2} \mathrm{P}^{\mathrm{P}} \mathrm{P}^{\mathrm{P}} \mathrm{C}$

D10

D30

D60
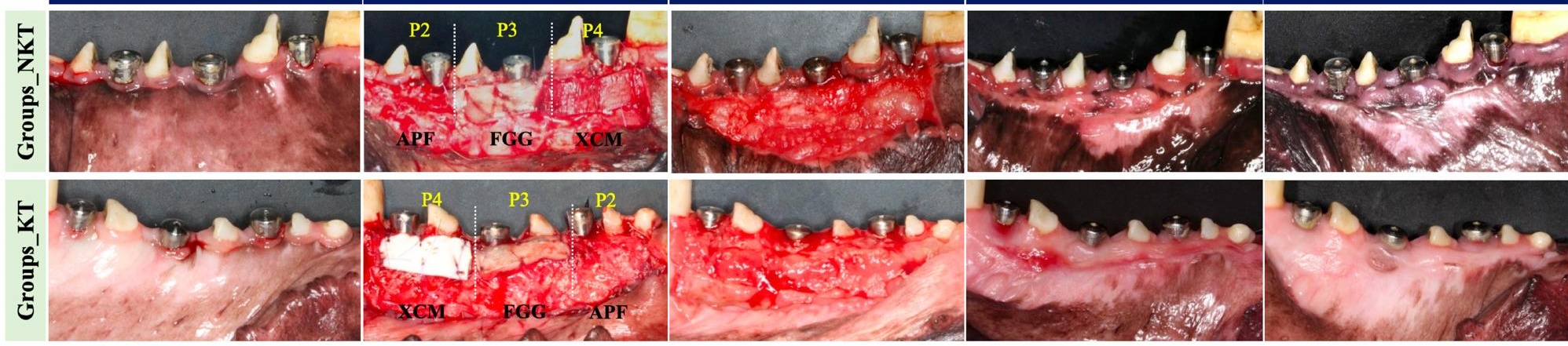
Tooth sites

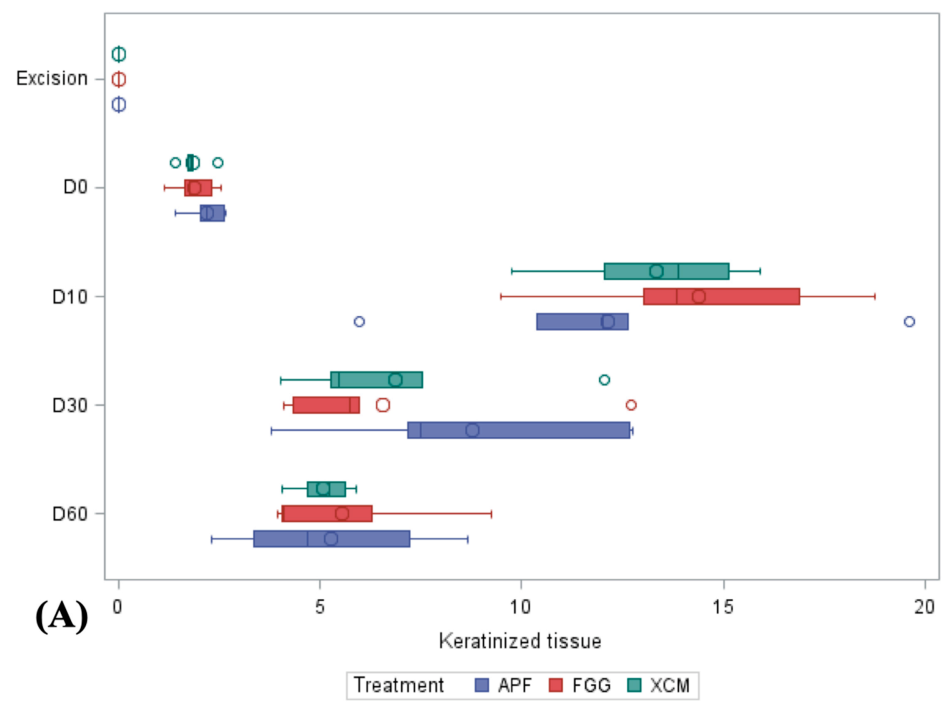

Implant sites

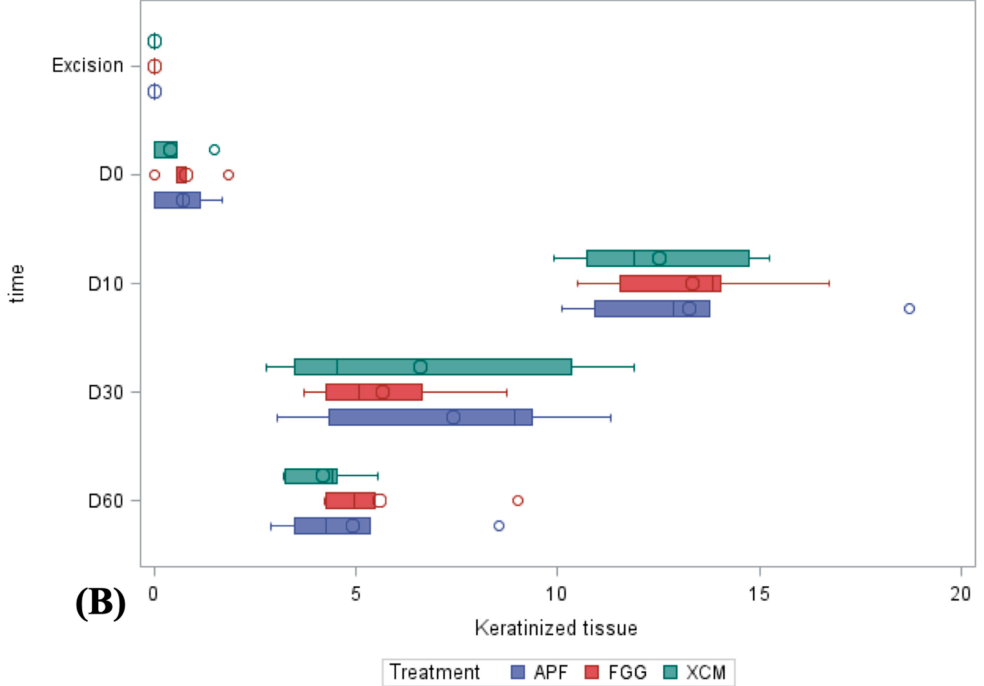


Tooth sites

(A)

Keratinized tissue

Treatment

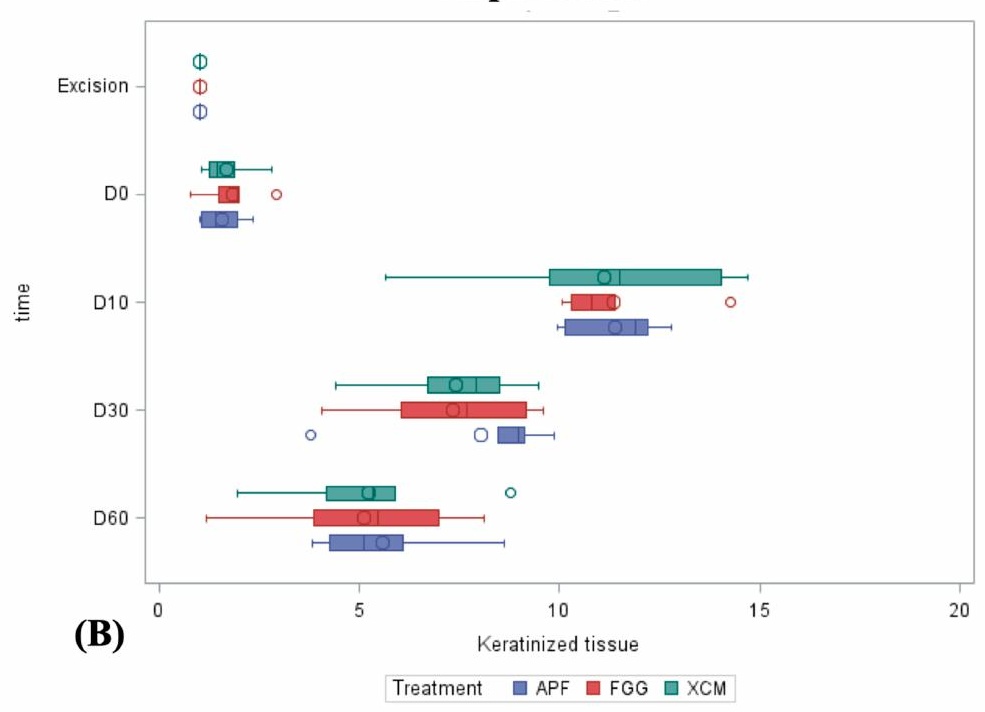

